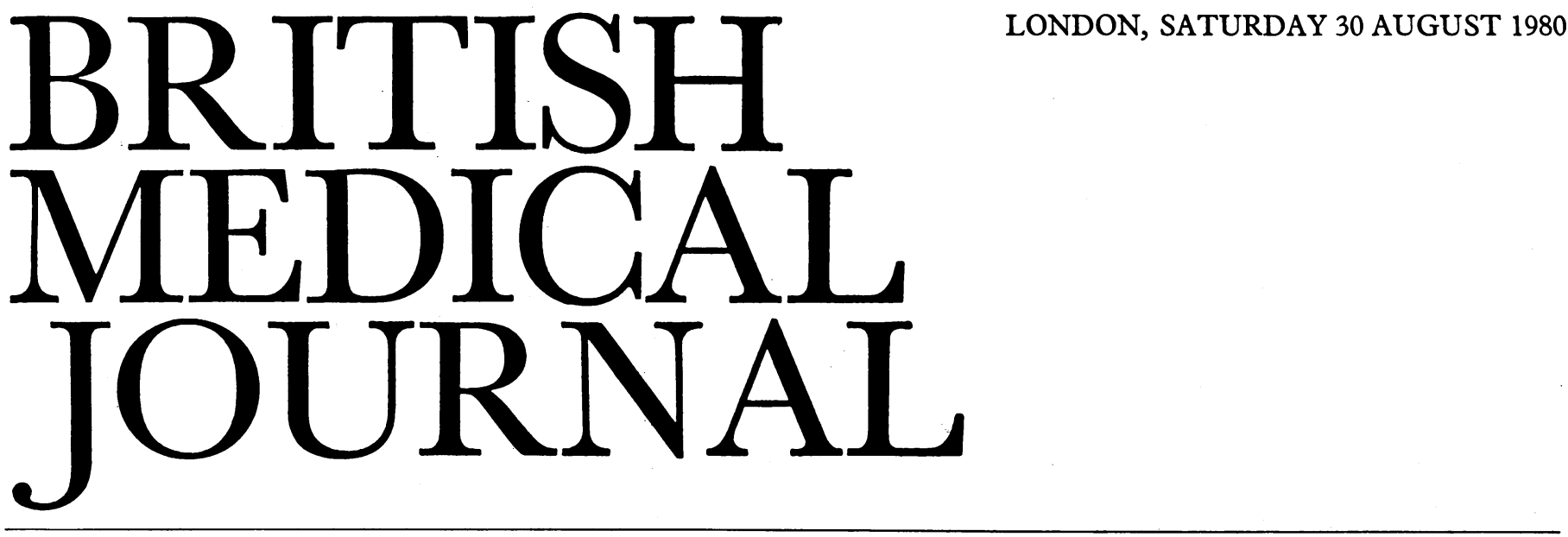

\title{
Bacterial resistance to trimethoprim
}

Trimethoprim is now available in Britain for the treatment and prophylaxis of urinary tract infection. As a result the debate has been renewed on the value of combined folate inhibitor preparations, notably co-trimoxazole-in particular, on the potential for emergence of trimethoprim resistance in bacteria exposed to the drug. When first marketed in 1969 preparations of sulphamethoxazole and trimethoprim were chosen primarily because the combination showed greater antibacterial activity than the individual components; the part played by each drug in minimising risks of acquired resistance was of secondary importance. ${ }^{1}$ Since then, the original claimsthat sequential blockade of bacterial folate synthesis produces synergism and hence superior clinical activity, and that the two agents protect each other from the development of bacterial resistance-have been challenged, and these issues have been examined in recent reviews. ${ }^{2} 3$

Trimethoprim is considerably more active than sulphamethoxazole against most bacterial species, ${ }^{1}$ and in the treatment of urinary tract infection the activity of trimethoprim is so dominant as to be almost entirely responsible for the activity of co-trimoxazole. ${ }^{4-6}$ Clinical trials have shown that in most urinary tract infections trimethoprim alone is as effective as co-trimoxazole and causes fewer side effects. ${ }^{78}$ Clearly, there is a persuasive case for evaluating trimethoprim in urinary tract infections, but doubts have been raised on the grounds that its widespread use might promote bacterial resistance. ${ }^{9-11}$

Trimethoprim acts by selectively inhibiting bacterial dihydrofolate reductase and so depleting folate, an essential cofactor in the biosynthesis of nucleic acids. Some species have intrinsic resistance to the drug: for example, in Pseudomonas aeruginosa a permeability barrier denies it access into the cell. Another mechanism protects the Neisseria species and anaerobes, in which the dihydrofolate reductase is relatively insusceptible to trimethoprim. Acquired resistance may be mediated by changes in dihydrofolate reductase making it less susceptible to inhibition by trimethoprim. Such changes may be determined by genes located either on the bacterial chromosome or as plasmid-borne $\mathbf{R}$ factors (extrachromosomal fragments of DNA capable of mediating transmissible resistance). Resistance determined by $\mathrm{R}$ factors is characteristically very high, raising minimal inhibitory concentrations of trimethoprim to $1000 \mathrm{mg} / 1$ or more. Another suggested mechanism for mediating resistance to trimethoprim might be that it facilitates selection of mutant thymine-dependent bacteria, a specialised group, highly resistant to trimethoprim, which require exogenous thymine or thymidine for DNA synthesis. ${ }^{12}$ However, despite the widespread use of cotrimoxazole, thymine-dependent bacteria have not become noticeably more prominent. Their persistence may be favoured in sites of chronic sepsis, associated with poor antibiotic penetration, where inflammatory exudates might provide a thymine source. ${ }^{12}$

In Britain the proportion of pathogens sensitive to trimethoprim has remained high ${ }^{13}$ despite increasing use of cotrimoxazole since its introduction in 1969. Resistance was reported in $2.5 \%,{ }^{14} 2.9 \%,{ }^{15} 3.2 \%,{ }^{16}$ and $4.3 \%{ }^{10}$ of coliform bacilli in surveys conducted between 1971 and 1979 in various centres. Nevertheless, a trend towards increasing trimethoprim resistance in hospitai isolates has been observed by Amyes and colleagues ${ }^{17}$ : trimethoprim resistance in urinary isolates rose from $9.5 \%$ in 1975 to $12.9 \%$ in 1977 . A notable feature has been the high proportion of Klebsiella and Enterobacter species among resistant isolates. ${ }^{1016}$ Of Gram-positive bacteria which may be implicated in urinary tract infections, $30 \%$ of Staphylococcus epidermidis and $1.6 \%$ to $4.1 \%$ of Staph aureus in Britain are currently resistant to trimethoprim. ${ }^{13}$

How valid is the claim that sulphamethoxazole protects trimethoprim from the acquisition of resistance? Over half of hospital Gram-negative bacilli are resistant to sulphamethoxazole, ${ }^{13} 18$ so that, in effect, many may already have been widely exposed to trimethoprim alone. Nevertheless, acquired resistance to trimethoprim is unusual despite the widespread use of co-trimoxazole, which remains a highly successful antimicrobial. Synergy between the two drugs occurs in vitro against sulphonamide-resistant Escherichia coli (except against those with an extremely high level of resistance ${ }^{19}$ ). Studies have shown that resistance may be induced when large inocula of bacteria are exposed to increasing concentrations of trimethoprim, presumably because only few cells can mutate to a higher level of resistance. Resistance could not be induced as readily when organisms were trained in the presence of both sulphonamide and trimethoprim. ${ }^{20}$

Selection of trimethoprim-resistant organisms in the flora of the gut does not seem to be a feature of treatment with cotrimoxazole or trimethoprim, ${ }^{72122}$ even long term, perhaps because of the definite suppression of coliform flora caused by both drugs. Though trimethoprim may suppress the emergence of sulphonamide resistance in patients receiving cotrimoxazole the reverse seems not to occur. ${ }^{22} \mathrm{~A}$ recent survey, ${ }^{23}$ with disquieting results, from the Turku area of Finland, where trimethoprim has been used for five years, 
found resistance to trimethoprim in $20 \%$ of isolates from urinary infections in outpatients and in $40 \%$ from inpatientsfigures which contrast dramatically with a rate of less than $1 \%$ in Helsinki between 1972 and 1977, possibly because since its release in Finland in 1973 trimethoprim has not been as widely used. ${ }^{24}$

Though plasmid-mediated resistance seems to be much less common than chromosomal resistance, ${ }^{10} 13$ and accounted for only $10 \%$ of resistant strains in the Turku study, ${ }^{23}$ some authors have commented recently on a disturbing increase in the proportion of resistant organisms carrying trimethoprimresistance plasmids. ${ }^{1517}$ Plasmids conferring resistance to trimethoprim and sulphonamides were first recognised in 1971. ${ }^{25}$ At present, their natural frequency in Britain appears to be low, 1126 but the potential for dissemination of trimethoprim resistance in response to use of the drug is a possible threat to the continued success of treatment with trimethoprim alone. Plasmids differ in their ability to disseminate, but under suitable conditions they may give rise to epidemics of resistance. An outbreak of plasmid-borne trimethoprim resistance in London has been associated with heavy use of co-trimoxazole, sulphonamides, and ampicillin but was controlled by isolation of the patients and restriction of antibiotic use. ${ }^{27}$ Plasmid-encoded trimethoprim resistance in epidemic strains of bovine Salmonella typhimurium has provided further evidence that we need strict regulations to control the use of antibiotics in farming. ${ }^{28}$

The increasingly high proportion of strains being found with high-level, non-transferable resistance implies that genes for trimethoprim resistance may be transposed from plasmid to bacterial chromosome ${ }^{15}$ - a disturbing possibility, since resistance of this kind is stable and (unlike plasmid-mediated resistance) not likely to be lost when selective pressures from antibiotics are removed.

Clearly, trends in susceptibility to trimethoprim need to be monitored carefully. Diagnostic laboratories reporting antimicrobial sensitivities should test both sulphonamide and trimethoprim, not only co-trimoxazole, and should be aware of possible sources of error-in particular, heavy inocula which may suggest spurious resistance on disc testing, a notorious problem with folate antagonists. The resistance of organisms showing reduced zones in such tests should be confirmed by determinations of minimum inhibitory concentrations. ${ }^{13}$

The effectiveness and lack of toxicity of trimethoprim are useful properties for a urinary antimicrobial, particularly where long-term prophylaxis is required. It may yet find wider applications, perhaps in treating respiratory infections or enteric fever. Since antibiotic pressures may dispose to acquisition of trimethoprim resistance further appraisal may suggest that the drug's usefulness may best be preserved by using it primarily for treatment of infections in the community and controlling its use in hospitals.

${ }^{1}$ Bushby SRM. Combined antibacterial action in vitro of trimethoprim and sulphonamides. The in vitro nature of synergy. Postgrad Med $\mathcal{F} 1969$; 45, suppl: 10-8.

2 Grüneberg RN. The microbial rationale for the combination of sulphonamides with trimethoprim. I Antimicrob Chemother 1979;5,suppl B: 27-36.

${ }^{3}$ Brumfitt W, Hamilton-Miller JMT. Trimethoprim. Br f Hosp Med 1980 March:281-8.

4 Greenwood D. Relevance of in vitro synergy to therapy: does synergy between diaminopyrimidines and sulphonamides operate at concentrations achievable in urine? $\mathcal{f}$ Antimicrob Chemother 1979;5,suppl B: 85-9.

5 Stokes A, Lacey RW. Effect of thymidine on activity of trimethoprim and sulphamethoxazole. $\mathcal{F}$ Clin Pathol 1978;31:165-71.

- Anderson JD, Lacey RW, Lewis EL, Sellin MA. Failure to demonstrate an advantage in combining sulphamethoxazole with trimethoprim in an experimental. model of urinary infection. $\mathcal{f}$ Clin Pathol 1974;27:619-22.
7 Brumfitt W, Pursell R. Double-blind trial to compare ampicillin, cephalexin, co-trimoxazole, and trimethoprim in treatment of urinary infection. $\mathrm{Br}$ Med $\mathcal{F} 1972$;ii :673-6.

${ }^{8}$ Koch UJ, Schumann KP, Küchler R, Kewitz H. Efficacy of trimethoprim, sulfamethoxazole and the combination of both in acute urinary tract infections. Clinical and pharmacokinetical studies. Chemotherapy 1973; 19:314-22.

${ }^{9}$ Busk HE, Korner B. Trimethoprim resistance in Finland. Br Med $\mathcal{f} 1980$; 280:1054-5.

${ }^{10}$ Brumfitt W, Hamilton-Miller JMT, Grey D. Trimethoprim-resistant coliforms. Lancet 1977; ii :926.

11 Towner KJ, Pearson NJ, Cattell WR, O'Grady F. Chromosomal resistance to trimethoprim. Lancet 1978 ; i:1371.

12 Maskell R, Okubadejo OA, Payne RH, Pead L. Human infections with thymine-requiring bacteria. $\mathcal{F}$ Med Microbiol 1978;11:33-45.

${ }^{13}$ Hamilton-Miller JMT. Mechanisms and distribution of bacterial resistance to diaminopyrimidines and sulphonamides. $\mathcal{F}$ Antimicrob Chemother 1979 ; suppl B:61-73.

14 Lacey RW, Bruten DM, Gillespie WA, Lewis EL. Trimethoprimresistant coliforms. Lancet $1972 ; \mathrm{i}: 409-10$.

15 Towner KJ, Pearson NJ, Pinn PA, O'Grady F. Increasing importance of plasmid-mediated trimethoprim resistance in enterobacteria: two sixmonth clinical surveys. Br Med $\mathcal{F} 1980 ; 280: 517-9$.

${ }^{16}$ Grey D, Hamilton-Miller JMT, Brumfitt W. Incidence and mechanisms of resistance to trimethoprim in clinically isolated Gram-negative bacteria. Chemotherapy $1979 ; 25: 147-56$

17 Amyes SGB, Emmerson AM, Smith JT. R-factor mediated trimethoprim resistance; result of two three-month clinical surveys. $\mathcal{F}$ Clin Pathol $1978 ; 31: 850-4$.

18 Pearson NJ, Towner KJ, McSherry AM, Cattell WR, O'Grady F Emergence of trimethoprim-resistant enterobacteria in patients receiving long-term co-trimoxazole for the control of intractable urinary-tract infection. Lancet 1979 ;ii:1205-8.

19 Grüneberg RN. The use of co-trimoxazole in sulphonamide-resistant Escherichia coli urinary tract infection. F Antimicrob Chemother 1975;1: 305-10.

${ }^{20}$ Darrell JH, Garrod LP, Waterworth PM. Trimethoprim: laboratory and clinical studies. $\mathcal{F}$ Clin Pathol 1968;21:202-9.

21 Grüneberg RN, Leakey A, Bendall MJ, Smellie JM. Bowel flora in urinary tract infection: effect of chemotherapy with special reference to co-trimoxazole. Kidney Int $1975 ; 8$, suppl S:122-9.

22 Toivanen A, Kasanen A, Sundquist H, Toivanen P. Effect of trimethoprim on the occurrence of drug-resistant coliform bacteria in the faecal flora. Chemotherapy 1976;22:97-103.

${ }^{23}$ Huovinen $\mathrm{P}$, Toivanen $\mathrm{P}$. Trimethoprim resistance in Finland after five years' use of plain trimethoprim. $B r M e d \mathcal{F} 1980 ; 280: 72-4$.

${ }^{24}$ Kasanen A, Anttila M, Elfving R, et al. Trimethoprim: pharmacology, antimicrobial activity and clinical use in urinary tract infections. Ann Clin Res 1978;10, suppl 22:1-39.

${ }^{25}$ Fleming MP, Datta N, Grüneberg RN. Trimethoprim resistance determined by $\mathrm{R}$ factors. $\mathrm{Br}$ Med $\mathcal{F} 1972 ; \mathrm{i}: 726-8$.

${ }^{26}$ Jobanputrra RS, Datta N. Trimethoprim R factors in enterobacteria from clinical specimens. 7 Med Microbiol 1974;7:169-77.

27 Grüneberg RN, Bendall MJ. Hospital outbreak of trimethoprim resistance in pathogenic coliform bacteria. $\mathrm{Br} M e d \mathcal{F} 1979$;ii:7-9.

28 Threfall EJ, Ward LR, Ashley AS, Rowe B. Plasmid-encoded trimethoprim resistance in multiresistant epidemic Salmonella typhimurium phage types 204 and 193 in Britain. Br Med f 1980;280:1210-1.

\section{Oestrogen-replacement treatment in old age}

The endocrine aspects of aging ${ }^{1}$ are attracting much current interest; but perhaps the topic of greatest clinical concern is hormone replacement in postmenopausal women. The value of oestrogen treatment for some menopausal symptoms is undisputed, but what of continued oestrogen replacement into old age? What are the advantages and risks of such treatment for the elderly postmenopausal woman, and how justified is present enthusiasm, at least in the United Stateswhere a recent survey showed that $24 \%$ of women over 70 were receiving oestrogens. ${ }^{2}$

The main gain from treatment with oestrogens continued into old age is the prevention of osteoporosis. Osteoporosis and fractures are major problems in elderly women; onequarter of all white women have osteoporotic vertebral 